\title{
Could T-wave and T peak-end interval be a new prognostic marker for patients receiving after cardiac resynchronization therapy?
}

\author{
Songül Usalp ${ }^{1}$ and Ramazan Gündüz ${ }^{1}$
}

${ }^{1}$ Affiliation not available

December 23, 2020

\begin{abstract}
Background:In this study, we investigated predictors of favourable responses to CRT using electrocardiography parameters in heart failure patients. Methods : Seventy-two patients with heart failure, sinus rhythm, left bundle branch block and receiving CRT were included in the study. Patients were classified as "responders" with an improvement in ejection fraction of $10 \%$ and "non-responders" as any patient not meeting this definition. Electrocardiograms were evaluated before and after 6 months CRT implantation. Results: There was no difference between responder and non-responder groups in terms of age, co-morbidities, medications, pre-implantation ECG parameters $(\mathrm{p}>0.05)$. A number of women CRT-responders higher than non-responder (25.4\% vs $6 \%, \mathrm{p}=0.026)$, and NYHA Class III patients dominantly in CRT-responder groups (36.9\% vs $29.2 \%$, p=0.014, respectively).Post-implantation QRS duration ( $143.3 \pm 18.6$ vs $160.1 \pm 29.2 \mathrm{~ms})$, cQT interval $(474.8 \pm 43.4$ vs $502.7 \pm 49.6$ $\mathrm{ms})$, T-wave $(165.6 \pm 25.7 \mathrm{vs} 192.1 \pm 25.0 \mathrm{~ms})$ and $\mathrm{T}$ peak-end $(82.9 \pm 13.2$ vs $98.1 \pm 13.3 \mathrm{~ms})$ values were very shorter in CRT responders group $(\mathrm{p}<0.05)$. In univariate regression analyses showed shortening of QRS, QT interval, T-wave, Tpeakend interval associated with favourable response to CRT $(\mathrm{p}<0.05)$. The receiver operating characteristics curve analyses were showed the optimal cut-off T-wave $<182 \mathrm{~ms}$, with $76 \%$ sensitivity, $75 \%$ specificity, and Tpeak-end interval $<92$ ms with 80 $\%$ sensitivity, for the favourable response CRT $(\mathrm{p}<0.05)$. Conclusion: QRS duration and QT interval narrowing are known to be associated with favourable outcomes, although the T-wave duration and $\mathrm{T}$ peak-to-end interval may also be considered in heart failure patients to predict a favourable CRT response.
\end{abstract}

\section{Hosted file}

CRT- Twave main man 19.12.20.pdf available at https://authorea.com/users/384680/articles/ 500205-could-t-wave-and-t-peak-end-interval-be-a-new-prognostic-marker-for-patientsreceiving-after-cardiac-resynchronization-therapy 